\title{
Pyrolysis-gas chromatography-mass spectrometry of isolated, synthetic and degraded lignins
}

\author{
C. SAIZ-Jimenez." ${ }^{*}$ and J. W. DE LeEuw ${ }^{2}$ \\ 'Direccion General de Medio Ambiente. Junta de Andalucia. Sevilla, Spain, and Centro de' \\ Edafologia. C.S.1.C. Sevilla. Spain \\ 'Department of Chemitry and Chemical Engineering. Organic Geochemistry Unit, Delft University \\ of Technology. de Vries van Heystplantsoen 2, $2628 \mathrm{RZ}$ Delft, The Netherlands
}

\begin{abstract}
Curie-point pyrolysis-gas chromatography-mass spectrometry was applied to study the chemical structure of sound and fungus degraded. industrial and synthetic lignins. Pyrolvsis products reflected in some detail the structural units present in the lignin polymer. Thus, sound spruce lignin yielded trans-isoeugenol coniferaldehyde and trans-coniferyl alcohol as major pyrolysis products. Biodegraded lignin yielded oxidized units, including vanillin. acetoguaiacone. methyl vanillate. propioguaiacone, vanilloyl methyl ketone and vanillic acid as major products. Kraft lignin also showed evidence of oxidation. although not as much as the biodegraded lignin. Major products from this industrial lignin were guaiacol. methylguaiacol. vinylguaiacol and homovanillic acid. Results indicated that synthetic lignin duplicates fairly well the structure of natural lignin. However, coniferylaldehyde and trats-coniferyl alcohol were the dominant products only from the synthetic lignin, indicating the presence of large amounts of coniferyl alcohol and coniferylaldehyde end groups.
\end{abstract}

Key words: pyrolysis, lignins, hicdegradation, kraft lignin. DHP lignin, spruce lignin

\section{INTRODLCTIOY}

Lignins are phenolic polymers which occur as major components of vascular plants and hence can be considered as markers of land-derived organic matter in lacustrine and marine sediments.

Lignins are biosynthesized by an oxidative polymerization of three substituted cinnamyl alcohols: $p$-coumaryl-, coniferyl- and sinapyl alcohols (4-hydroxy-, 4-hydroxy-3-methoxy-and 4-hydroxy3.5-dimcthoxycinnamyl alcohol, respectively). The proportions of the three precursor alcohols differ between angiosperm and gymnosperm lignins (Adler, 1977).

Although a wide range of micro-organisms, especially fungi and bacteria, can decompose lignins to some extent, only certain higher fungi (Basidiomycetes) have been shown to decompose them extensively (Kirk and Fenn, 1982).

In soils, and probably also in sediments when present, lignins and/or their degradation products are thought to play an important role in the formation of humic substances (Saiz-Jimenez and de Leeuw, 198-4).

Besides the natural input of lignin in soils and sediments via plant debris, an anthropogenic origin of lignin has to be considered. In fact, industrial lignins, produced as side-products in chemical pulping, are often discharged into the environment. As industrial lignins appear to be resistant to microbial decomposition in a variety of neutral and acidic,

- Address for correspondence: Cesareo Saiz-Jimenez. Apartado 12.017, Sevilla, Spain. anoxic environments (Zeikus et al., 1982). their accumulation in polluted areas has to be taken into account.

The chemical nature of the lignins has been studied by often tedious chemical degradation techniques such as nitrobenzene, permanganate. cupric oxide oxidation or acidolysis. However, the structure of lignins can be analysed rapidly by analytical fash pyrolytic methods (Martin et al., 1979b; Obst. 1983; Schenck et al., 1983). In this paper, pyrolysis-gas chromatography-mass spectrometry (Py-GC-MS) for sound, fungus degraded and industrially modificd lignins is reported. Also, an artificial lignin synthesized in vitro from coniferyl alcohol using a peroxidase is included for comparative purposes. Because complex polymeric mixtures present in sediments and soils, coals, etc. are often studied by analytical pyrolytic techniques (Saiz-Jimenez ct al., 1979; Martin et al., 1979a; van de Meent et al., 1980; Schenck et $a l ., 1983)$ the understanding of the structures of pyrolysis products generated from different lignins will provide useful information about the origin of the lignin-related components most frequently identified in the various types of humic and other macromolecular materials. Moreover, a better understanding of the lignin structure after fungus mediated transformation can be obtained. and the structure of artificial lignin can be compared with that of natural lignins.

\section{EXPERIMFNTAL}

Spruce milled wood lignin and lignin degraded by Corioltus versicolor (L. ex Fr.) Quel, were kindly 
provided by Dr T. Kent Kirk. Characteristics of the wood used, the extraction procedures and the isolation and the incubation methods are reported by Kirk and Chang (1974). Moreover, chemical characterization studies of both lignins have been reported (Kirk and Chang. 1975).

Indulin AT, a pine kraft lignin with an ash content less than $1 \%$, was kindly provided by $\mathrm{Dr} J$. Marton. Details of its chemical structure are described elsewhere (Marton, 1964; Marton and Marton, 1964).

The synthetic lignin, guaiacyl DHP (dehydrogenative polymerisate). was kindly supplied by Dr $O$. Faix. Its synthesis is described by Schweers and Faix (1973).

\section{Pyrolysis-GC}

The samples were suspended in methanol. One droplet of the suspension $(\sim 10-20 \mu \mathrm{g}$ of sample) was applied to a ferromagnetic wire with a Curie temperature of $510^{\circ} \mathrm{C}$.

The pyrolysis gas chromatographic analyses were carried out using a pyrolysis unit similar to the one described by Meuzelaar et al. (1975), modified for use at high temperatures (van de Meent et al., 1980). Chromatographic separations were achieved with a capillary glass WCOT column $(28 \mathrm{~m} \times 0.5 \mathrm{~mm}$ i.d. $)$ coated with CP sil 5 ( $1.3 \mu \mathrm{m}$ film thickness) using a Packard Becker 419 gas chromatograph. Helium was used as the carrier gas.

\section{Pyrolysis-GC-MS}

Pyrolysis was performed as described above. The pyrolysis products were separated on a capillary glass WCOT column $(28 \mathrm{~m} \times 0.5 \mathrm{~mm}$ i.d. $)$ coated with $\mathrm{CP}$ sil $5\left(1.25 \mu \mathrm{m}\right.$ film thickness) held at a rate of $5^{\circ} \mathrm{C}$ $\min ^{-1}$. Helium was used as the carrier gas. The chromatograph (Varian model 3200) was coupled to a Varian Mat 44 mass spectrometer operated in the EI mode at $80 \mathrm{eV}$ with a cycle time of $2 \mathrm{~s}$.

\section{RESULTS AND DISCUSSION}

Pyrograms of the sound spruce lignin, the biodegraded spruce lignin, the industrial lignin and the synthetic lignin are shown in Figs 1-4.

The structural elucidation of the pyrolysis products (Table 1) was based on comparison of both retention time data and mass spectral data with those of standards, and with literature data.

The pyrogram of spruce lignin (Fig. 1) shows several major peaks, identified as 4-methylguaiacol (6), 4-vinylguaiacol (9), vanillin (12), transisoeugenol (15), coniferaldehyde (27) and transconiferyl alcohol (29). Coniferylaldehyde and coniferyl alcohol were not reported in previous Py-GCMS studies (Martin et al., 1979b; Philp el al. , 1982) of spruce lignin, but were recently identified from pine lignin by Obst (1983). Other prominent pyrolysis products identified in the spruce lignin pyrogram were guaiacol (4), eugenol (10), homovanillin (14), acetoguaiacone (16), propioguaiacone (22) and homovanillic acid (25). All of these pyrolysis products seem to refiect structural units present in the lignin polymer.

It is noteworthy the presence of methyl vanillate (19) among the pyrolysis products of lignins. Obst (personal communication) treated loblolly pine MWL with $1 \mathrm{~N} \mathrm{NaOH}$ at $100^{\circ} \mathrm{C}$, which would cleave all carboxylic esters. The pyrogram of the saponified MWL showed about the same amount of methyl vanillate as the untreated MWL. Therefore, it appears that methyl vanillate is an artefact produced during pyrolysis and does not represent methyl esters in lignin. Apparently vanillic acid is methylated during pyrolysis.

The distribution pattern of the pyrolysis products encountered in the fungus degraded lignin (Fig. 2) is very different from the pattern observed in the sound lignin (Fig. 1). Major components in the biodegraded lignin are guaiacol (4). acetoguaiacone (16), methyl vanillate (19) and vanilloyl methyl ketone (23). Other prominent peaks were identified as 4 vinylguaiacol (9), vanillin (12), propioguaiacone (22) and vanillic acid (24). The total absence of coniferaldehyde and trans-coniferyl alcohol, the relatively low intensity of 4-methylguaiacol, 4-vinylguaiacol and trans-isoeugenol and the presence of vanilloyl methyl ketone and vanillic acid among the pyrolysis products of the fungal degraded lignin is good evidence for oxidation of the $C_{j}$-alkyl chain at the $C_{\alpha}$ and $C_{\beta}$ positions, and for cleavage in the side-chain, mainly between $C_{\alpha}$ and $C_{\beta}$. These conclusions based upon the pyrolysis data are in good agreement with those of Chen et al. (1982, 1983) who studied the fungal degradation of spruce lignins by other methods.

The pyrogram of kraft lignin (Fig. 3) shows significant differences from that of natural conifer lignin. Major peaks were identified as guaiacol (4), 4methylguaiacol (6), 4-vinylguaiacol (9), trans. isoeugenol (15), and homovanillic acid (25). Other important pyrolysis products were identified as 4 ethylguaiacol (8), eugenol (10), vanillin (12), acetoguaiacone (16) and trans-coniferyl alcohol (29). The differences between the sound lignin and the kraft lignin are especially evident in the relatively high abundance of guaiacol, 4-methylguaiacol, 4vinylguaiacol and homovanillic acid in the latter.

During delignification of wood in the kraft process, the lignin component is solubilized via degradation and ionization to free the fiber for the manufacture of paper. The lignin alteration is characterized by degradation of the side-chain, including a partial loss of $C_{\gamma}$ atoms, $\beta$-guaiacyl ether bond cleavage. limited demethylation, and formation of stilbene structures from phenylcoumarans (Marton, 1964; Adler et al., 1964; Lundquist et al., 1977). These changes in the lignin structure are corroborated to some extent by the prominence of homovanillic acid together with the low intensities of coniferaldehyde and transconiferyl alcohol, in the pyrolysis mixture. 


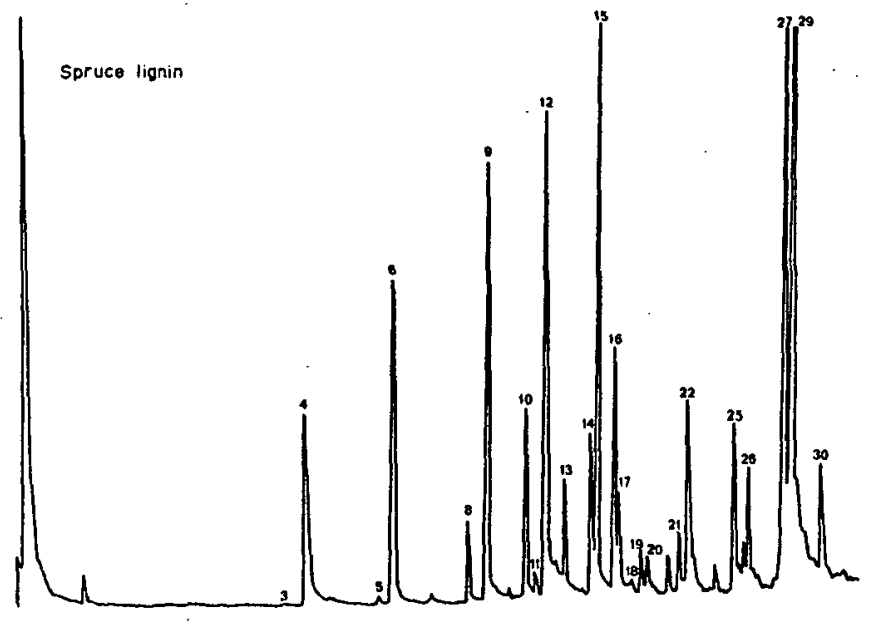

Fig. 1. Pyrogram of spruce milled wood lignin.

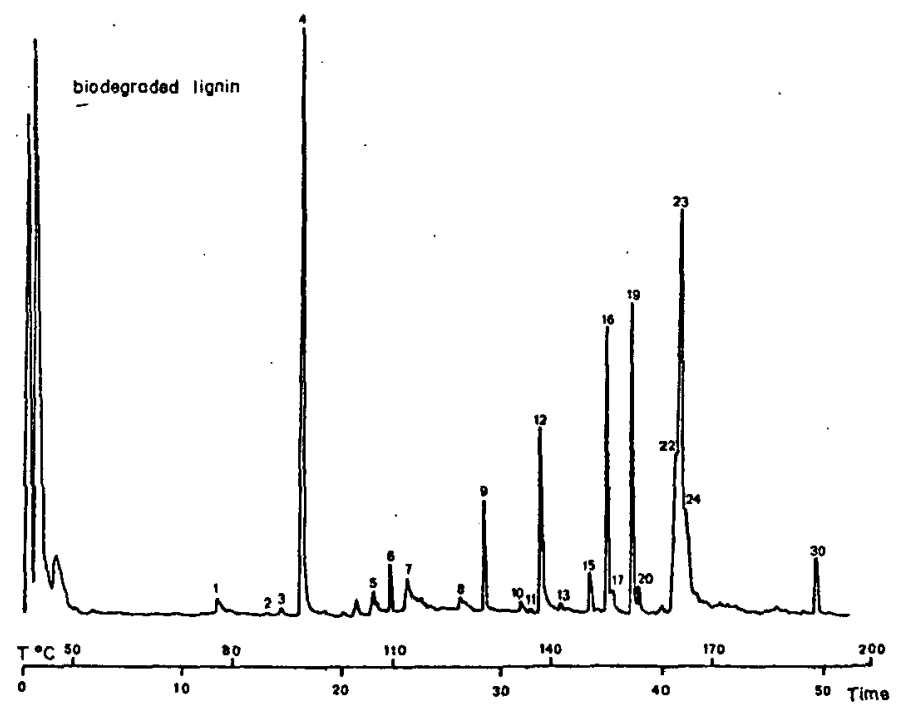

Fig. 2. Pyrogram of spruce milled wood lignin degraded by Coriohus versicolor.

Among the very volatile pyrolysis products of kraft lignin we encountered a number of organic sulphur compounds such as $\mathrm{H}_{2} \mathrm{~S}, \mathrm{SO}_{2} . \mathrm{CH}_{3} \mathrm{SH}, \mathrm{C}_{2} \mathrm{H}_{5} \mathrm{SH}$ and/or $\mathrm{CH}_{3}-\mathrm{S}-\mathrm{CH}_{3}, \mathrm{CH}_{3}$-S-S-CH 3 and $\mathrm{CH}_{3}-\mathrm{S}-\mathrm{S}$-S$\mathrm{CH}_{3}$. These pyrolysis products are very probably generated from the sulphur-containing alkyl sidechatin moieties present in the industrial lignin. This observation is in agreement with other work on kraft lignins (Marton, 1964).

The presence of characteristic sulphur-containing compounds, together with lignin pyrolysis products, can discriminate an anthropogenic origin of industrial lignins in recent sediments from a natural contribution of lignin or biodegraded lignins. Further, 


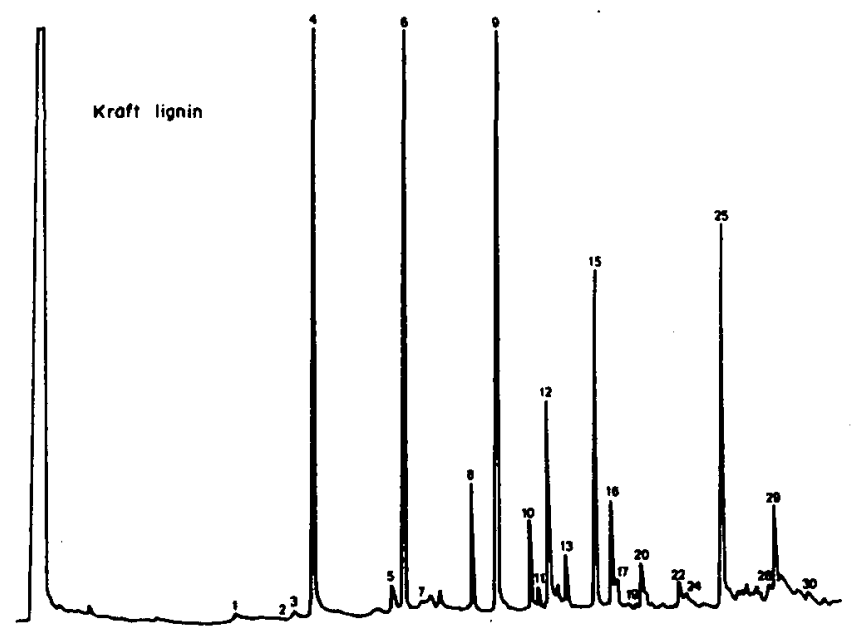

Fig. 3. Pyrogram of kraft lignin.

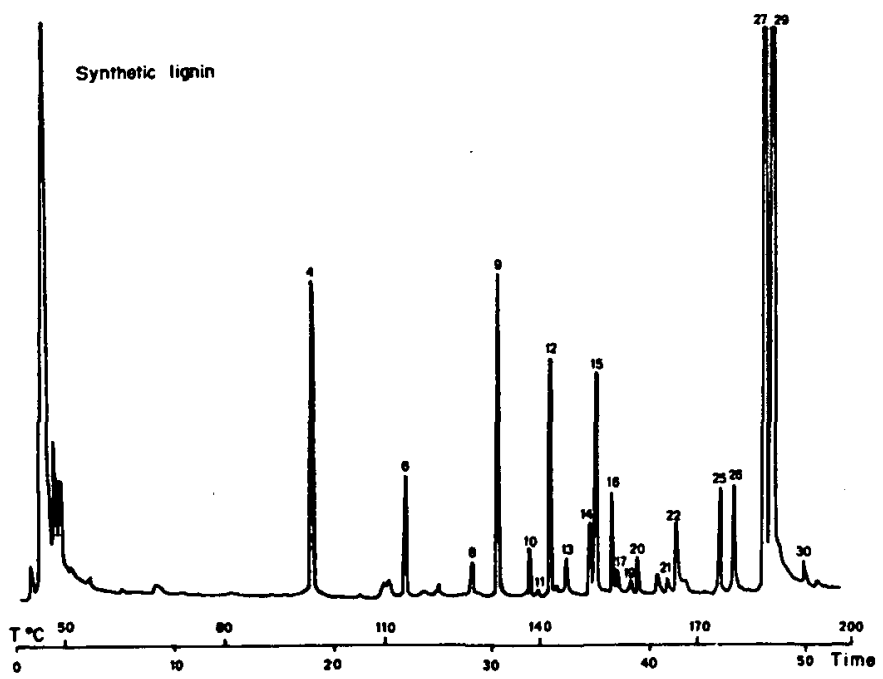

Fig. 4. Pyrogram of synthetic lignin.

characteristic lignin pyrolysis products most frequently identified in soil and aquatic humic substances and coals can be considered as polymeric biomarkers, indicating a plant origin.

Pyrograms of sound lignin (Fig. 1) and guaiacyl DHP (Fig. 4) are similar in that both have the same type of pyrolysis products. However, because the ratios of these products are different, it must be concluded that DHP and sound lignins are not identical, but merely similar. Compared to sound lignin the relative amounts of guaiacol (4), coniferaldehyde (27), and trans-coniferyl alcohol (29) are increased in DHP. Model DHP lignin as synthesized by the action of peroxidase on coniferyl alcohol 
Table 1. Pyrolysis products from lignins

\begin{tabular}{|c|c|c|c|c|}
\hline Puak No. & $R_{1}$ & $\mathrm{R}_{2}$ & $\mathbf{R}_{3}$ & Remarks \\
\hline 1 & $\mathrm{OH}$ & & & \\
\hline 2 & $\mathrm{OH}$ & $\mathrm{CH}_{3}$ & & \\
\hline 3 & $\mathrm{OH}$ & & $\mathrm{CH}_{3}$ & \\
\hline 4 & $\mathrm{OH}$ & $\mathrm{OCH}_{3}$ & & \\
\hline 5 & & & & Positional isomer of 6 \\
\hline 6 & $\mathrm{OH}$ & $\mathrm{OCH}_{3}$ & $\mathrm{CH}_{3}$ & \\
\hline 7 & $\mathrm{OH}$ & $\mathrm{OH}$ & & \\
\hline 8 & $\mathrm{OH}$ & $\mathrm{OCH}_{3}$ & $\mathrm{CH}_{2}-\mathrm{CH}_{3}$ & \\
\hline 9 & $\mathrm{OH}$ & $\mathrm{OCH}_{3}$ & $\mathrm{CH}_{2}=\mathrm{CH}_{2}$ & \\
\hline 10 & $\mathrm{OH}$ & $\mathrm{OCH}_{3}$ & $\mathrm{CH}_{2}-\mathrm{CH}=\mathrm{CH}_{2}$ & \\
\hline 11 & $\mathrm{OH}$ & $\mathrm{OCH}_{3}$ & $\mathrm{CH}_{2}-\mathrm{CH}_{2}-\mathrm{CH}_{3}$ & \\
\hline 12 & $\mathrm{OH}$ & $\mathrm{OCH}_{3}$ & $\mathrm{CHO}$ & \\
\hline 13 & $\mathrm{OH}$ & $\mathrm{OCH}_{3}$ & $\mathrm{CH}=\mathrm{CH}-\mathrm{CH}_{3}$ & cis \\
\hline 14 & $\mathrm{OH}$ & $\mathrm{OCH}_{3}$ & $\mathrm{CH}_{2}-\mathrm{CHO}$ & \\
\hline 15 & $\mathrm{OH}$ & $\mathrm{OCH}_{3}$ & $\mathrm{CH}=\mathrm{CH}-\mathrm{CH}_{3}$ & trans \\
\hline 16 & $\mathrm{OH}$ & $\mathrm{OCH}_{3}$ & $\mathrm{CO}-\mathrm{CH}_{3}$ & \\
\hline 17 & & & & (C) ${ }^{\mathrm{OCH}}$ ? \\
\hline 18 & $\mathrm{Cl}$ & $\mathrm{Cl}$ & $\mathrm{OCH}_{3}$ & $\mathrm{R}_{4}=\mathrm{OCH}_{3}$ \\
\hline 19 & $\mathrm{OH}$ & $\mathrm{OCH}_{3}$ & $\mathrm{COO}_{-} \mathrm{CH}_{3}$ & \\
\hline 20 & $\mathrm{OH}$ & $\mathrm{OCH}_{3}$ & $\mathrm{CH}_{2}-\mathrm{CO}-\mathrm{CH}_{3}$ & \\
\hline 21 & $\mathrm{OH}$ & $\mathrm{OCH}_{3}$ & $\mathrm{C}_{3} \mathrm{H}_{5} \mathrm{O}$ & \\
\hline 22 & $\mathrm{OH}$ & $\mathrm{OCH}_{3}$ & $\mathrm{CO}-\mathrm{CH}_{2}-\mathrm{CH}_{3}$ & \\
\hline 23 & $\mathrm{OH}$ & $\mathrm{OCH}_{3}$ & $\mathrm{CO}-\mathrm{CO}-\mathrm{CH}_{3}$ & \\
\hline 24 & $\mathrm{OH}$ & $\mathrm{OCH}_{3}$ & $\mathrm{COOH}$ & \\
\hline 25 & $\mathrm{OH}$ & $\mathrm{OCH}_{3}$ & $\mathrm{CH}_{2}-\mathrm{COOH}$ & \\
\hline 26 & $\mathrm{OH}$ & $\mathrm{OCHI}_{3}$ & $\mathrm{CH}^{-}=\mathrm{CH}-\mathrm{CH}_{2} \mathrm{OH}$ & cis \\
\hline 27 & $\mathrm{OH}$ & $\mathrm{OCH}_{3}$ & $\mathrm{CH}=\mathrm{CH}-\mathrm{CHO}$ & \\
\hline 28 & $\mathrm{OH}$ & $\mathrm{OCH}_{3}$ & $\mathrm{CH}_{2}-\mathrm{CH}_{2}-\mathrm{COOH}$ & \\
\hline 29 & $\mathrm{OH}$ & $\mathrm{OCH}_{3}$ & $\mathrm{CH}=\mathrm{CH}-\mathrm{CH}_{2} \mathrm{OH}$ & trans \\
\hline 30 & & & & dialkyl phthalate \\
\hline
\end{tabular}

appears to be similar to certain conifer lignins. However, Kirk et al. (1975) have shown that in the synthetic lignin the relative amounts of coniferyl alcohol end groups are more abundant and that the hatural lignin has a higher degree of cross-linking. These phenomena are supported by our pyrolysis data.

The dominant presence of coniferaldehyde and trans-coniferyl alcohol in the pyrogram of the DHP lignin point to a polymeric structure in which the original substrate (trans-coniferyl alcohol) is linked less firmly than in the natural lignin. In summary, we think that these synthetic lignins are very valuable models for the chemical study of many aspects of natural lignins.

\section{CONCLuStoNs}

(1) Pyrolysis-gas chromatography and pyrolysisgas chromatography-mass spectrometry are power- ful tools to rapidly chemically characterize isolated and synthetic lignins and lignin-derived polymers.

(2) Lignins and lignin-derived products can, therefore, be considered as polymeric biomarkers, less prone to external influences than extractable biomarker molecules.

(3) Biodegradation of lignin by white-rot fungi results in severe side-chain oxidation. These recognizably oxidized polymers are present among the building blocks of humic substances (Saiz-Jimenez and de Leeuw, 1984).

(4) An anthropogenic origin of lignin products in recent sediments, e.g. kraft lignin from papermills can be recognized and can be discriminated from a natural contribution of lignins or biodegraded lignins, based on pyrolysis data.

Acknowledgements-The authors wish to express their gratitude to DrT. Kent Kirk and Dr J. R. Obst for critically reading the manuscript. 


\section{REFERENCES}

Adler E. (1977) Lignin chemistry-past, present and future. Wood Sci. Technol. 11, 169-218.

Adler E., Falkehag I., Marton J. and Halvarson H. (1964) The behaviour of lignin in alkaline pulping. II. Model experiments with arylalkyl- $\beta$-aryl ethers. Acta chem. scand. 18, 1313-1314.

Chen C.-L., Chang H.-M. and Kirk T. K. (1982) Aromatic acids produced during degradation of lignin in spruce wood by Phanerochaete chrysosporium. Holzforschung 36, 3-9.

Kirk T. K. and Chang H.-M. (1974) Decomposition of lignin by white-rot fungi. I. Isolation of heavily degraded lignins from decayed spruce. Holzforschung 28, 217-222.

Kirk T. K. and Chang H.-M. (1975) Decomposition of lignin by white-rot fungi. II. Characterization of heavily degraded lignins from decayed spruce. Holz forschung 29, 56-64.

Kirk T. K. and Fenn P. (1982) Formation and action of the ligninolytic system in basidiomycetes. In Decomposer Basidiomycetes, pp. 66-90. British Mycological Society Symposium 4. Cambridge University Press, Cambridge.

Kirk T. K., Connors W. J., Bleam R. D., Hackett W. F. and Zeikus J. G. (1975) Preparation and microbial decomposition of synthetic ${ }^{14} \mathrm{C}$-lignins. Proc. natl. Acad. Sci. USA 72, 2515-2519.

Lundquist K., Kirk T. K. and Connors W. J. (1977) Fungal degradation of kraft lignin and lignin sulfonates prepared from synthetic ${ }^{14} \mathrm{C}$-lignins. Arch. Microbiol. 112, 291296.

Martin F., Saiz-Jimenez C. and Cert A. (1979a) Pyrolysisgas chromatography-mass spectrometry of humic fractions. II. The high boiling point compounds. Soil Sci. Soc. Am. J. 43, 309-312.

Martin F., Saiz-Jimenez C. and Gonzalez-Vila F. J. (1979b) Pyrolysis-gas chromatography-mass spectrometry of lignins. Holzforschung 33, 210-212.

Marton J. (1964) On the structure of kraft lignin. TAPPI 47, 713-719.

Marton J. and Marton T. (1964) Molecular weight of kraft lignin. TAPPI 47, 471-476.

van de Meent D., Brown S. C., Philp R. P. and Simoneit B.
R. T. (1980) Pyrolysis-high resolution gas chromatography and pyrolysis gas chroma tography mass spectrometry of kerogen and kerogen precursors. Geochim. Cos. mochim. Acta 44, 990-1013.

Meuzelaar H. L. C. Ficke H. G. and den Haring H. C. (1975) Fully automated Curie-point pyrolysis gas liquid chromatography. J. chromatogr. Sci. 13, 12-17.

Obst J. R. (1983) Analytical pyrolysis of hardwood and softwood lignins and its use in lignin-type determination of hardwod vessel elements. J. Wood Chem. Technol. (In press).

Philp R. P., Russell N. H., Gilbert T. D. and Friedrich J. M. (1982) Characterization of Victorian soft brown coal wood by microscopic techniques and Curie-point pyroly. sis combined with gas chromatography mass spec. trometry. J. Anal. appl. Pyrol. 4, 143-161.

Saiz-Jimenez C. and de Leeuw J. W. (1984) Pyrolysis gas chromatography mass spectrometry of soil polysaccharides, soil fulvic acid and polymaleic acid. In Advances in Organic Geochemistry 1983 (Edited by Schenck P. A., de Leeuw J. W. and Lijmbach G. W. M.). Org. Geochem. 6, 287-293.

Saiz-Jimenez C., Haider K. and Meuzelaar H. L. C. (1979) Comparisons of soil organic matter and its fractions by pyrolysis mass spectrometry. Geoderma 22, 25-37.

Schenck P. A., de Leeuw J. W., Viets T. C. and Haverkamp J. (1983) Pyrolysis mass spectrometry in coal chemistry: a study of the coalification of vitrites and the typification of Australian brown coals. In Petroleum Geochemistry and Exploitation of Europe (Edited by Brooks J.). Blackwell Scientific, Oxford (In press).

Schweers W. and Faix O. (1973) Vergleichende. Untersuchungen an Polymermodellen des lignins (DHP's) verschiedener Zusammensetzungen. I. Mitt. Herstellung von Lignin-Polymermodellen verschiedener Zusammen. setzung aus den drei Monolignolen p-Cumaralkohol, Coniferylalkohol und Sinapilalkohol. Holzforschung 27, 208-213.

Zeikus J. G., Wellstein A. L. and Kirk T. K. (1982) Molecular basis for the biodegradative recalcitrance of lignin in anaerobic environments. FEMS Microbiol. Leat. 15, 193-197. 